\title{
Managing Leader Learning Preferences at Work: A Practice-Oriented Approach
}

\author{
Charles D. Kerns \\ Pepperdine University \\ Corperformance, Inc.
}

A culture of learning is an organizational resource for creating and sustaining competitiveness while enhancing high-performance with high well-being. Managerial leaders can benefit by having a practical and systematic approach to understanding and managing their learning preferences. After a brief review of some relevant literature, a practice-oriented framework and proven six-step approach to applying this process is presented. Some benefits from applying this process are noted and an application example is offered. Some challenges that this approach presents such as increasing leader awareness of the value of managing learning preferences, breaking bad learning habits and integrating technology into efforts to actively engage leaders in managing learning preferences are noted.

Keywords: Organizational Culture, Managing, Performance, Well-Being, Executive Coaching

\section{INTRODUCTION}

The study of learning preferences, in the current context, draws from the learning sciences, and leadership literature (Hoadley, 2018; Ludvigsen \& Nerland, 2018; Clouse, Wilson \& Rizzo, 2019; Froehlich, Segers \& Van den Bossche, 2014). The learning sciences reflect an interdisciplinary approach to studying how people learn and how to support learning. Taken together, the study of learning and leadership holds promise to help organizational leaders better understand their own approach to learning which will likely, in turn, assist them in managing the learning preferences of their people. ${ }^{1}$ While the process of learning and managing learning preferences can be examined on both the individual and organizational level, this article will focus on managing learning preferences relating to the individual leader and his development. In this article leader learning preferences relate to learning styles, learning identities/mindsets, cycles of learning and learning spaces. Leaders at all organizational levels as well as aspiring leaders can likely benefit from understanding and applying learning preferences at work.

Leaders who can effectively facilitate and manage learning likely help enhance and sustain organizational competitiveness (Swift \& Hwang, 2008; Larrea, Aranguren \& Valdaliso, 2017). Given the extensive amount of change that organizations face on many fronts, a culture of learning and innovating become critical organizational resources. Organizational leaders are integral in managing the learning process for increased innovation, performance and well-being (Aragón-Correa, Garcia-Morales \& Cordon-Pozo, 2007; Kerns, 2018a). By skillfully managing their own and others' learning preferences, as part of facilitating learning at work, they also enhance motivation and engagement levels (Renninger, Ren \& Kern, 2018; Kerns, 2014). 
Richards and Marshall (2019) applied experiential learning theory to a workforce issue relating to a growing gap between the need for employees with digital marketing skills and the current supply of industry ready talent in the labor market. This situation is brought on by the large amounts of digital transformation that organizations are engaging in which requires their employees as well as prospective new hires to have digital marketing skills. This work helps demonstrate how experiential learning processes can be applied in coordination with marketing technology resources to help address an important workforce need.

As applied in the current article, "learning" in the context of managerial leadership is defined as follows:

\section{The acquisition of knowledge and skills to help facilitate understanding and manage change to enhance performance and well-being.}

This definition draws from the field of experiential learning and in the context of managerial leadership includes the ideas of change management, performance, well-being and continuous learning. Experiential learning views learning as a holistic process of adaptation resulting from interactions between the individual and situational circumstances that produce understanding and knowledge (Passarelli \& Kolb, 2011). This perspective has application value for managerial leaders as they strive to better understand and manage relevant aspects of the learning process in the workplace. The concept espoused by experiential learning theory, that understanding and managing experience is essential to the learning process for creating knowledge (Kolb, 1984), fits closely with the two key leadership dimensions of individual differences and situational context. A leader's experience and learning style preferences are both individual difference making factors associated with the study and practice of leadership (Kerns, 2015a; Kerns, 2018b). Situational context is also a core dimension of leadership that influences leaders' learning at work (Kerns, 2015b; Oc, 2018).

Kolb (1984), as a pioneer in the field of experiential learning, has developed a four-phased experiential learning cycle. The four phases are as follows:

Phase 1: Concrete Experience (CE) which represents a mode of learning relating to how an

$\downarrow \quad$ individual understands or "takes in" new experiences or reconsiders existing experience through active engagement in such activities as on-the-job experience, training, demonstrations and simulations.

Phase 2: Reflective Observation (RO) which represents a mode of learning for transforming $\downarrow \quad$ or dealing with experience by reflectively connecting experience and ideas through activities such as observation, conversation, and/or small group discussion.

Phase 3: Abstract Conceptualization (AC) also represents a mode of learning relating to how an individual understands or "takes in" experience like in CE (Phase 1), but instead of focusing on active engagement with concrete experience, this mode concentrates on learning from the experience by thinking using logical reasoning and conceptualizing. The reflection (RO) leads to a new idea or a change of an existing abstract conceptualization in this AC phase.

Phase 4: Active Experimentation (AE) also represents a mode of learning for transforming or dealing with experience like RO (Phase 2) but instead of focusing on thinking, this mode relates to learning by doing or acting through practice and implementation.

The experiential learning process is depicted in these four phases. Conceptually, the individual systematically works through learning experiences by engaging in all four modes of learning i.e. experiencing/having an experience (Phase 1), observing/reflecting on the experience (Phase 2), thinking/generalizing from the experience (Phase 3), and acting (Phase 4). These four modes of learning become part of a dynamic process that is not only influenced by situational context but is also sensitive to the nature of what is being learned. Ideally, a learner solves problems and tackles challenges by engaging sequentially in each of the four phases of the experiential learning cycle. In practice, however, individuals have unique learning style preferences for the four different learning modes, i.e. CE, 
$\mathrm{RO}, \mathrm{AC}, \mathrm{AE}$. Based on their dispositional/genetic endowment, life experiences, and situational contexts individuals typically develop preferences for one of the four learning modes relating to experiencing, reflecting, thinking or acting (Tannenbaum, Beard, McNall \& Salas, 2012).

Research has identified five additional types of learning styles which are frequently observed and can be configured around the four learning modes captured in the four-phase experiential learning cycle (Kolb, 2017). These five styles include:

- Initiating action using a hands-on approach when dealing with situational circumstances. These individuals tend to rely on intuition more than logical analysis. This style represents a combination of the $\mathrm{CE}$ and $\mathrm{AE}$ modes of learning found in the four-phase experiential learning cycle.

- Imagining alternatives through watching and viewing situations from different perspectives. These individuals tend to be sensitive and prefer to observe rather than take action. This style consists of a combination of the $\mathrm{CE} / \mathrm{RO}$ modes of learning found in the four-phase experiential learning cycle.

- Analyzing by integrating ideas into frameworks and systems upon reflection. This assimilating style is characterized by watching and thinking. This style combines the AC-RO modes of learning found in the four-phase experiential learning cycle.

- Deciding using conceptual frameworks in making decisions to solve problems and set action plans. These individuals prefer experimenting with new ideas in order to make practical applications. They are thinkers and doers and represent a combination of the AC/AE modes of learning found in the four-phase experiential learning cycles.

- Balancing shown by considering the advantages and disadvantages of acting vs. reflecting and experiencing vs. thinking. Individuals with this style balance all four of the learning modes found in the four-phase experiential learning cycle i.e. Phase $1-\mathrm{CE}$, Phase $2-\mathrm{RO}$, Phase $3-\mathrm{AC}$, and Phase $4-\mathrm{AE} .^{2}$

Sternberg (1997) has identified some useful general characteristics of style that can be applied to the previously noted learning styles:

- Styles are preferences, not abilities. There is a difference between how skilled a person is and how much an individual prefers/likes to do something.

- Styles are more of a question of fit between the facilitator of learning and learner; styles are neither good nor bad.

- Individual stylistic preferences vary in strength and flexibility.

- Styles can vary and change over one's lifespan.

- Styles are measurable and influenced by situational context.

Leaders who understand their learning style preferences and the connection between these preferences and the demands of the situation will be able to enhance learning that helps drive desired outcomes such as increased competitiveness in target markets, innovation and future learning.

It is the author's observation in working with leaders over the past several decades that many do not understand nor proactively manage their unique way of learning, especially their learning style preferences. This view is also shared by others who study and practice in the field of learning and development in organizational settings (Passarelli \& Kolb, 2011). These observations also relate to the study of fixed identity versus learning identity/growth mindset (Heslin, 2010; Putz, Schilling, Kluge \& Stangenberg, 2012; Dweck, 2006). It seems that people have implicit or lay theories about themselves and others (Molden \& Dweck, 2006; Schyns, Kiefer, Kerschreiter \& Tymon, 2011). These implicit theories include, for example, how people view leadership effectiveness and how they see themselves as learners. Some people have fixed views of themselves when it comes to assessing their abilities and attributes. Individuals at the extreme negative end of the fixed identity spectrum do not believe they can learn. In contrast, those who believe they can learn and develop have a learning identity or growth mindset. In 
terms of managing learning, it seems important for leaders to embrace and foster the development of learning identities/growth mindsets at work. Leaders who can understand and manage learning style preferences and encourage learning identities/growth-oriented mindsets, in particular, will likely be affording themselves and their organization a competitive advantage by helping to create a culture of learning.

While there is growing evidence of the value of learning in organizational settings, the extant literature offers limited resources for leaders looking for practice-oriented frameworks and tools to guide their efforts at leading learning and managing learning style preferences in workplace setting. Most of the work surrounding "styles" considers leadership styles and related thinking styles (Mumford \& Higgs, 2020; Sternberg \& Zhang, 2005; Akhavan, Zahedi, Dastyari \& Abasaltian, 2014). Also, the extensive work relating to individual differences does not significantly consider the role of leaders in shaping and managing organizational learning (Zaccaro, Green, Dumbrow \& Kolze, 2018). It seems useful to advance the work connecting learning preferences to leadership in workplace settings.

A managerial leader can benefit by having a practice-oriented framework and approach to managing learning preferences. The study of how an individual's unique learning preferences may impact behavior and performance holds promise to the field of leadership and leader development (Andreadis, 2009; Michie \& Zumitzavan, 2012; Turesky \& Gallagher, 2011). This work has application value across functional roles, leadership positions and organizational settings. The current article is intended to provide an approach for practitioners to adapt and for applied researchers to investigate further. Seasoned professionals and emerging leaders are offered on integrated practice-oriented framework and application example to help increase their effectiveness at managing learning preferences for a competitive advantage.

This important topic of managing leader learning preferences is explored using information gleaned from the "real world" of business practice (Locke, 2007; Locke \& Cooper, 2000). The framework is intended to help managerial leaders more effectively understand and manage their unique learning preferences in a way that contributes to their development and effectiveness while helping to advance their organizations' competitiveness and innovation (Leavy, 1999; Tran, 2008; Kharabsheh, Jarrar \& Simeonova, 2015). This work also helps contribute to the rather sparse extant literature relating to practice-oriented evidence-based approaches to managing leader learning preferences.

\section{LEADER LEARNING PREFERENCES-MANAGEMENT CYCLE}

A practice-oriented framework is provided that helps organizational leaders manage their learning preferences. The author has developed an integrated managerial leadership system that is associated with a leadership framework for managing learning preferences. ${ }^{3}$ This framework has been applied in different settings including work organizations, executive education and field studies.

As discussed in this article, learning preference management seeks to help leaders identify, affirm and optimize their learning preferences so that they can integrate them into their daily lives to optimize workplace performance and well-being. The Leader Learning Preferences Management Cycle depicted in Figure 1 helps operationalize the definition of learning, learning style preferences and related processes in a general way.

This practice-oriented framework draws upon a review of relevant literature, applied research, and decades of study and practice by the author and his colleagues. This work has identified the following observations that serve to support the framework offered in this article.

- Managing learning preferences connects with all functional work areas and leadership roles across diverse industries.

- The study and practice of managing leader learning preferences is advanced through interdisciplinary collaboration by experts in fields such as learning sciences, leadership and business education (Herrenkohl \& Polman, 2018). 
- Emerging trends for leaders in the field of marketing relating to areas such as planning, customer satisfaction, and Customer Relationship Management (CRM) software, present significant opportunities for organizational learning and learners to apply their skills in assessing and effectively managing learning and learning work style preferences (Migliore, Howard, \& Gray, 2018).

- The increasing need for digital marketing skills in the field of marketing may be effectively addressed by applying experiential learning theory in partnership with business and educational programs (Richards \& Marshall, 2019; Zahay, Altounian, Pollitte, \& James, 2019).

- Research in neuroscience has application value for the practice of managing leader learning (Fabritius \& Hagemann, 2017; Swart, Chisholm \& Brown, 2015; Zull, 2002).

- Understanding and managing leader work preferences is part of more fully understanding one's working identity (Clapp-Smith, Hammond, Lester \& Palanski, 2019).

- Leaders typically do not understand or proactively manage their learning style preferences (Passarelli \& Kolb, 2011).

- Individual differences are relevant to the study and practice of leader learning preferences especially as they relate to experience, situational context and learning style preferences (Kerns, 2018b; Kerns, 2015a; Pashler, McDaniel, Rohrer \& Bjork, 2009).

- The assessment of leadership core values and strengths can be helpful in assessing, affirming and understanding a leader's learning preferences (Kerns, 2016; Kerns, 2017a; Kerns, 2010).

- Experiential learning theory and applications are foundational to the practice of managing leader work style preferences (Kolb, 1984; Kolb \& Kolb, 2005; Passarelli \& Kolb, 2011).

- How an individual learner "takes in" or understands an experience and "deals with" or transforms experience helps determine her learning style preferences (Kolb 1984).

- Experiencing, reflecting, thinking and acting are fundamental modes around which individualistic styles evolve (Passarelli \& Kolb, 2011; Kolb, 2017).

- Individual stylistic preferences vary in strength and flexibility (Mainemelis, Boyatzis \& Kolb, 2002).

- Situational contexts and learning spaces interact with a leader's learning style preferences (Kerns, 2015b; Fazey \& Marton, 2002; Kolb \& Kolb, 2005).

- Effective management of leader work style preferences can enhance organizational motivational and engagement levels (Renninger, Ren \& Kern, 2018).

- There is a difference between ability and leadership related style preferences (Sternberg, 1997).

- Fixed identity vs. learning identity/growth-oriented mindset is part of an individual's preferences for learning (Dweck, 2000; Molden \& Dweck, 2006).

- Developing a performance profile can benefit organizations striving to create and sustain a learning-oriented culture. The human capital valuation process can be effectively anchored by performance profiles that link learning to important key result areas such as product innovation and cross-functional collaboration (Kerns, 2001).

- Leader learning preferences and thought leadership as processes which help leaders produce wise outcomes for increased competitiveness deserve further study by practitioners and applied researchers (Kerns, 2019a).

- The development of behavioral practices associated with displaying leadership presence at work can be facilitated by the effective management of learning preferences (Kerns, 2019b). 


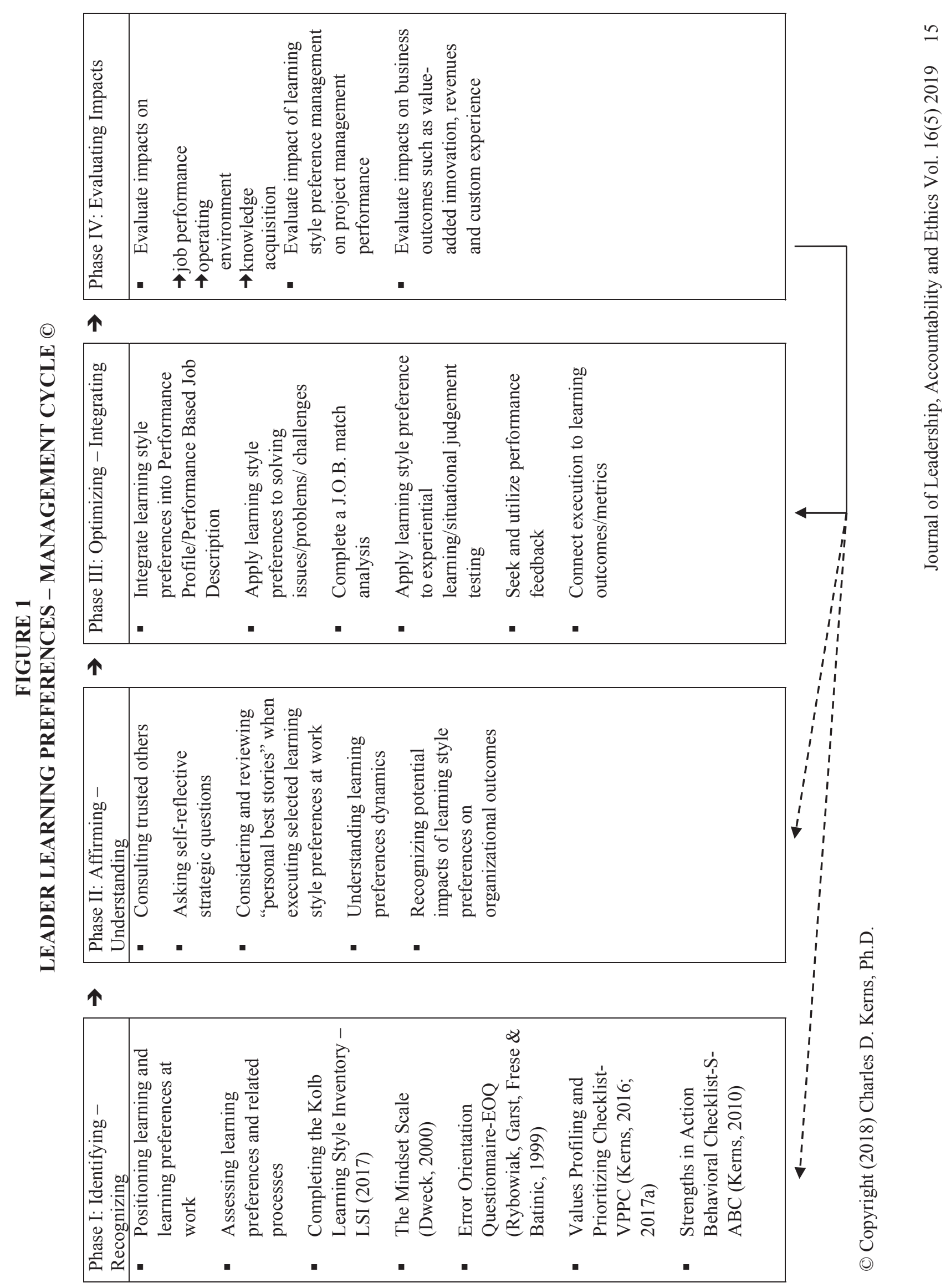




\section{Phases of Leader Learning Preferences - Management Cycle}

The leader learning preferences-management cycle framework has four phases, reviewed below. Key content areas and activities associated with each phase are briefly discussed. Implementation of the framework is typically facilitated by an executive coach or trusted advisor.

\section{Phase I: Identifying - Recognizing}

There are a variety of written materials and assessment tools available to help leaders identify and assess their learning preferences (Coffield, Moseley, Hall \& Ecclestone, 2004). The Kolb Learning Style Inventory (KLSI), for example, is widely used to help identify learning style preferences. The KLSI consists of a twelve-item instrument. As previously noted, it is based on experiential learning theory and centers around a four phased learning cycle which is used to identify nine types of learning style preferences (Kolb, 2017). In addition, the Mindset Scale (Dweck, 2000) consists of a seven-item instrument which assesses an individual's fixed or growth mindset identity. It has been found that basic assumptions about learning and development significantly influence leaders' and employees' perceptions of failure (Dweck, 2006; Heslin, 2010; Bligh, Kohles \& Yan, 2018). It seems that the ability to learn from errors plays a key role in organizations where the need for change and innovation are constant as competitive pressures (Putz, Schilling, Kludge \& Stangenberg, 2012). Leaders with growth mindsets likely positively impact and promote learning at work. A growth mindset coupled with the effective management of learning style preferences helps a leader create and sustain learning at work as a valueadded resource which offers a competitive advantage. Additional assessment tools relating to a leader's core values and strengths have proven useful in helping leaders recognize and more fully understand their learning preference styles (Kerns, 2016; Kerns 2017a; Kerns, 2010).

\section{Phase II: Affirming - Understanding}

After identifying one's learning style preferences and more fully recognizing the roles that these preferences play in learning at work, it is essential that they be affirmed and understood. This affirmation process helps the leader better understand his learning style preferences and mindset for learning. These consultations should be with "trusted others" who know the individual well and are willing to give honest feedback. This dialogue should help the individual better understand how his identified learning style preference and learning mindset may be reflected in his behavior. Also, in affirming the identified learning style preference and learning mindset, strategic reflective questions such as "Do I feel energized, and authentic while expressing them?" should be asked. Reflecting on "personal best" stories, or situations where the leader has performed exceptionally well while displaying the learning preference, is also a useful way to help affirm and more fully understand an identified learning preference (Roberts, 2013). Connecting personal best stories to achievement of desired business outcomes is useful. If reassessment appears to be warranted after this process, then the individual should re-assess his learning style preferences and learning mindset, then proceed accordingly with a fuller understanding of himself on this individual difference making dimension.

\section{Phase III: Optimizing-Integrating}

After identified learning preferences and mindsets have been affirmed, many useful things can be done to help optimize and integrate the execution of those preferences into one's work. For example, the execution of learning style preferences is supported by the development and integration of those preferences into a Performance Based Job Description/Performance Profile (Kerns, 2001). Performance profiles can be used to help match position requirements with individuals' learning preferences. Learning preferences can additionally be used to help assess matches between an individual's preferred operating environment and her bosses' work style preferences to determine compatibility levels. The experience gleaned from using learning style preferences in new and challenging ways is invaluable to the development of those preferences. Learning preferences, especially those not preferred, likely need to be used to help optimize situational learning. The acquisition of knowledge and the enhancement of skills related to applying one's learning preferences and growth mindset are key optimizing tactics. Obtaining 
useful feedback on how effectively one is executing her learning preferences is important to optimizing and integrating the development of learning style preferences at work. Situational judgement testing can be effectively applied to help leaders optimize their skills in applying learning preference concepts and practices at work (Fritzsche, Stagl, Salas \& Burke, 2006).

\section{Phase IV: Measuring-Evaluating}

Measuring and evaluating the impact that one's learning preferences management efforts are having on the attainment of key results and other important outcomes is a key component in the cycle. Measuring and evaluating performance and well-being are especially important in determining if leaders are effectively executing the management of their learning preferences at work. When a leader executes his learning style preferences and learning mindset effectively, a variety of important outcomes are positively impacted. Feedback gleaned from this measurement and evaluation process also becomes a basis for making behavioral changes and/or adjustments to optimize and integrate the execution of learning preferences at work (Phase III).

\section{THE VALUE OF MANAGING LEARNING}

The process of competently managing learning preferences at work using a systematic approach offers a number of benefits. Organizational learning and the ability of leaders to manage learning preferences help organizations and their people proactively anticipate and align with their needs for change (Adreadis, 2009; Shimoni, 2017; Venus, Stam \& van Knippenberg, 2019). Organizations that treat the process of learning as an important organizational resource and process experience increased innovation, and enhanced customer loyalty, and produce more competitive results for their shareholders (DiBella, 2001). With increased global competition, technological innovations and the knowledge economy, leaders who are able to better understand and manage their learning style preferences while facilitating organizational learning will likely create competitive advantages for key stakeholders.

Integral to talent management and people development is the acquisition of competencies at work. Managerial leadership competencies have been extensively studied and are essential to creating and sustaining organizational and leadership effectiveness (Kerns \& Ko, 2014). Learning is a key process in helping to develop competent leaders and workforces. Effectively managing leader learning style preferences can be useful in developing the following five interpersonal influence managerial leader competencies (Kerns \& Ko, 2014):

1. Self-awareness and control

2. High-impact communicating

3. Understanding work preferences

4. Managing conflict and negotiating

5. Decisive problem solving

Closely connected to organizational learning and managing the learning process is the study of thought leadership and knowledge management (Kerns, 2019a). The process of learning, like the process of managing thought leadership and knowledge, is an organizational resource which likely advances organizational wisdom, competitive advantage, and sustainable success when leaders effectively engage their enterprise in the learning process relating to understanding and managing learning preferences. When organizational leaders better understand how they prefer to take in experience (learning from specific concrete experiences vs. learning by thinking) and deal with experience (learning by doing vs. learning by reflecting), they become more effective in advancing learning through knowledge acquisition and skill enhancement. Taken together, managing learning and thought leadership can greatly benefit organizations by helping to underscore the importance of appreciating wisdom as a key metric. Viewing wisdom as a value-added outgrowth of learning in a business and organizational context seems to be beneficial for leaders and their organizations. Seeing learning and thought leadership efforts translated 
into wise outcomes with practical utility that contribute to enhancing competitiveness is worthy of further study by both practitioners and applied researchers.

The study and practice of managing learning style preferences relates to the field of individual differences. Individual differences are a key dimension of leadership (Zaccaro, Green, Dubrow \& Kolze, 2018; Kerns, 2015a). Helping leaders better understand who they are as leaders in relevant practice areas is important. With new understandings and perspectives leaders can increase their personal effectiveness in their respective roles. Managing leader learning style preferences at work, as an individual difference making factor, can help a leader increase her self-knowledge and effectiveness. This developmental work also contributes to advancing behavioral diversity in the workplace. When it comes to managing behavioral diversity, a leader's effectiveness is likely enhanced when she can recognize that individual differences play a key role at work, including learning style preferences. Fabritius and Hagemann (2017) provide a neuroleadership perspective and caution that working in teams of people with similar mindsets and learning style preferences or dispositions can influence the brain to become complacent, causing performance to suffer and opportunities for innovation to be reduced. With this in mind, organizational leaders can contribute and enhance behavioral diversity by developing their knowledge and skills relating to managing different learning preferences at work and using that knowledge to foster behavioral diversity in work groups.

Additionally, mounting evidence about the benefits of well-being in the workplace shows that it is important for leaders to understand and manage well-being at work (Tomkins \& Pritchard, 2020). Managerial leaders can play a key role in positively impacting their own and others well-being (Kerns, 2018a; Caza \& Wrzesniewski, 2013). Fostering and managing engagement represents an opportunity for leaders to enhance well-being. More specifically, the practice of showing interest in employee development and learning can enhance well being (Kerns, 2018a). When organizations support and invest in their leaders learning how to manage their own and others' learning style preferences, well-being is likely enhanced. Organizations that show interest in employee learning and development are contributing to the enhancement of well-being.

Further, teamwork effectiveness can benefit from leaders who understand how to manage key factors such as individual members' learning style preferences and how these preferences can impact team performance (Kerns, 2019c). Team leaders can use individual member profiles to create a team's learning style profile. This process will help the individual member leverage and optimize his work style preference to enhance team performance. It will also help the team and its leader to identify the team's strengths as well as opportunities for growth as it relates to learning. Project management work will also benefit from leaders who are competent in managing learning style preferences (Wyrick, 2003).

\section{A SIX STEP APROACH}

To put further practical utility to managing leader learning preferences concepts provided in this article, the following six step approach is offered as a specific adaptation of the Leader Learning Preferences - Management Cycle. This process, developed in the context of executive coaching to help leaders focus on their learning preference, provides one approach by which organizational leadership may become, and/or lead their people to become, higher performers with higher well-being (Kerns, 2018a).

\section{Step 1: Positioning Managing Learning Preferences}

The first step in the six-step process is intended to serve as the "motivating preamble" to initiating a managing leader learning preferences program. The coach should review some of the benefits of this approach, orient the client to this systematic and interactive process, and seek to gain commitment for using the approach from the participant being coached. 


\section{Step 2: Identifying and Clarifying Learning Preferences}

Using appropriate assessment tools, which may include those previously noted in the discussion of the Leader Learning Preferences - Management Cycle (e.g., the Kolb Learning Style Inventory, The Mindset Scale, Values Profiling and Prioritizing Checklist, and Strengths in Action Behavioral Checklist), the executive coach will facilitate the client in identifying and clarifying his learning style preferences, then discuss what his style looks like in behavioral terms when executed at work.

\section{Step 3: Affirming and Understanding Learning Preferences}

Once the relevant learning style preferences have been identified and are understood, ask the client to do at least three things to affirm that the assessment accurately represents her learning preferences. First, the leader will share her learning style preference and mindset for learning with several "significant others" - people who know the leader well and who will be willing to offer honest feedback regarding how much they see the learning style and learning mindset being displayed by the individual. Second, ask the leader to answer a number of strategic self-reflective questions relating to the identified learning style preferences and learning mindset. These questions often include, "What evidence do you have that this learning style preference and learning mindset really reflect your approach to learning?" and "How have you specifically displayed your learning style preference and learning mindset at work in the past three months?" This affirmation process helps the individual better understand her preferences. Third, ask the leader to reflect on situations (two or three are recommended) when the leader was her personal best and to describe how her learning preferences helped to make the outcome a "personal best." The goal is to have the client to (1) affirm that the learning preferences are accurate, and (2) understand her learning preferences and how they can be used for enhanced impact at work.

\section{Step 4: Personal Best Stories}

Since individuals are typically unaccustomed to explicitly talking about their learning style preferences, ask the leader to recall and relay several personal best stories that exemplify how his learning style preferences have been used in specific situations to "bring out" his personal best (Roberts, 2013). If the leader has had limited experience in explicitly applying the identified preferences at work, facilitate the leader to generate stories of how he sees learning style preferences being applied in specific situations in the future. This step is important to help further affirm and understand learning style preferences as well as to optimize and integrate learning style preferences at work.

\section{Step 5: Design a Performance Profile or Performance-Based Job Description}

Facilitate the client in developing a one to three-page performance profile or performance-based job description for the client's current position, integrating the individual's learning preferences into this performance management document (Kerns, 2001). Performance profiling helps managerial leaders focus on the most important things that they can directly influence in their respective positions. This helps focus and further optimize the individual's work in managing learning style preferences and integrating them into the current work role. With the use of performance profiling, leaders can further advance and sustain momentum to create a learning-oriented organizational culture that focuses human capital on measurable value creation. The individual valuation process can be supported by performance profiles that link leader learning and knowledge building actions to important key results/impacts such as product innovation, enhancing customer experience, and effective cross-functional collaboration. Also, the client can be asked to discuss how her learning preferences match her Job, the Opperating culture and her Bosses' preferences i.e. the J.O.B. match analysis.

\section{Step 6: Execute, Coach and Connect to Key Results/Outcomes}

Using a self-coaching or executive coaching approach, each individual is introduced to the Leader Learning Preferences Management Cycle and asked to regularly review and evaluate how well he is managing the identified preferences at work. This evaluation includes a review of the progress in attaining 
desired impacts relating to such areas as job performance, learning outcomes and value-added innovations.

\section{APPLYING THE SIX STEP APPROACH - AN EXAMPLE}

To illustrate and assist in putting the Six Step Approach to use, the following example is offered. David is the President of a division in a large global organization. He has five key reports and he reports to the CEO for Global Operations. In the context of executive coaching, what follows is the adaptation/customization of the Six Step Approach to Leader Learning Preferences Management to David's situation in his role as division President. ${ }^{4}$ This program was part of a larger innovation/change management consulting program within his division.

\section{Step 1: Positioning Managing Learning Preferences}

The executive coach oriented David to the overall Six Step Approach and highlighted a number of benefits that this approach offered him. Benefits that were reviewed included:

- He would be able to serve as a positive performance role model for learning to help establish a learning-oriented knowledge enhancing organizational culture that creates and sustains innovation.

- David would be able to identify his learning style preferences and have a systematic way to focus on and manage his preferences for greater impact.

- This evidence-based approach underscores the benefits in managing learning preferences at work.

- With coaching, David could learn to apply this approach with his five key reports.

- This approach would help directly drive his key result of increasing the number of people displaying high performance with high well-being in his division, starting with himself.

- David would have a more focused way of measuring and evaluating impacts as it relates to executing his learning preference style at work.

After reviewing each of the program steps, David was probed for his level of commitment for completing this program. His commitment level was very high; he was especially interested in exploring how he could be coached to apply this process with his five key reports.

\section{Step 2: Identifying and Clarifying Learning Preferences}

David was asked to complete the Kolb Learning Style Inventory, the Core Values Profiling and Prioritizing (CVPPC), The Mindset Scale and the Strengths in Action Behavioral Checklist (S-ABC). In consultation with the executive coach, David identified the following five areas that related to his learning and learning preferences:

- His preference for "acting" as a preferred learning style.

- A growth mindset/learning identity that was underdeveloped.

- An opportunity for engaging more in the reflection mode when addressing key topics and challenges.

- A need to better understand and manage the learning preferences of his reports to enhance innovation.

- A strong alignment between his core values, strengths and passion for learning.

The above areas along with some related findings became the focus of his leader learning preferences management development program. 


\section{Step 3: Affirming and Understanding Learning Preferences}

While David was quite confident that he had identified his learning style preferences accurately and understood them, he was asked to do two things to affirm and to perhaps even more fully understand them. First, he identified several trusted individuals who knew him well to comment on whether they saw him displaying these learning preferences at work. He sought input from his boss, his reports and two peers from another division within his company. Second, he was asked to respond to the following question with regard to his learning style preference, using an excess rating scale (Kaiser \& Overfield, 2010) where a zero rating (0) equals displaying the preference in the "just right amount", $+5=$ "way too much" and -5 = "way too little": To what extent do I take action to solve problems, issues, challenges?

His consultations with others and his ratings and associated comments to the strategic question affirmed to David that his learning preferences were accurate and that he was using "taking action and executing" to excess. He also affirmed his passion for learning (learning identity/growth mindset) with an understanding that he may be underutilizing this part of his identity.

\section{Step 4: Personal Best Stories}

To help optimize and integrate his learning preferences and to further affirm them, David was asked to describe several personal best stories which indicate how he displays his preferences at work. One of the personal best stories that he shared and linked to his learning preferences concerned how he as chair of a global innovation task force was able to get the group to develop and execute several key strategic projects which helped increase new product development and drive revenues. He detailed how this situation drew upon his learning preference for taking action. He also disclosed how he displayed his learning preference for action by proactively crafting a new position of Director of Innovation. He not only designed the position performance profile but spearheaded the recruitment efforts and selection process.

\section{Step 5: Design a Performance Profile or Performance-Based Job Description}

David and the employees in his division had previously completed a performance-based job description, or performance profile, as part of the installation of a Performance Management System. This tool specified the key results, key actions, people and technical skills for which each employee was held accountable. As part of the Six Step Approach, David modified the previous version of his performance profile, editing the wording of several key actions which were associated with his agreed upon key results. These edits, for example, added "engaging others in discussions" and "exploring options when making critical strategic decisions," to his performance profile as key actions intended to positively impact his key results. The addition of these two areas helped to strengthen his key actions related to the key result of increasing innovation and revenues from new products within his division, while providing more balance to his learning style preference for "action".

\section{Step 6: Execute, Coach and Connect to Key Results/Outcomes}

With his executive coach, David reviewed the Leader Learning Preference - Management Cycle focusing on the "Optimizing and Integrating" and "Evaluating Impacts" components. David was coached to apply the six-step approach with his direct reports. He especially wanted support in facilitating his key reports in identifying and clarifying their learning preferences and on the development of their personal best stories. To this end, David and his coach also regularly engaged in development sessions which utilized situational judgement testing. As part of step six, David and his coach regularly evaluated how he was doing in executing his learning style preferences and how these efforts were impacting his key result areas, especially relating to increasing the number of high performers with high well-being and producing wise value-added outcomes. Special attention was given to bringing balance to his use of learning style preferences by coaching him to situationally adapt by showing the "just right amounts" of acting, reflecting, experiencing, and thinking.

This Six Step Approach is straightforward, practitioner-oriented, and provides a systematic approach to enhancing an individual's management of learning preferences for performance and well-being 
enhancement. This field work also demonstrates that this process can be delivered using a "coach the coach" method, as was done with David as he worked with his key reports with the support of this executive coach.

\section{SOME CHALLENGING ISSUES}

Managing learning preferences offers some challenges for organizations and their leaders. There is a need to increase the awareness of the value of managing learning and learning style preferences at work. Leaders could benefit from seeing themselves as teachers and lifelong learners (Finkelstein, 2018; Kerns, 2018b). For leaders to become skilled facilitators of learning they will need to acquire basic skills and knowledge on how to effectively motivate and develop the adult learner (Knowles, Holton, \& Swanson, 2015). This represents a significant challenge in the light of Dweck's work (2000) and the recognition by Passarelli and Kolb (2011) that many individuals are unaware of their learning style preferences and are not knowledgeable about how to foster others learning at work. There is a need to have leaders not only work to better understand their approach to learning but to also strive to create and sustain organizational cultures characterized by strong learning identities/growth oriented mindsets. Organizations over time take on the characteristics of their leaders so it seems important that leaders become positive role models for understanding and managing learning preferences while projecting a strong growth mindset/learning identity. Leaders and their organizations are challenged to enhance their awareness and competence in managing learning preferences. A laudable goal would be for leaders to see managing learning preferences as part of their leader identity (Miscenko, Guenter, \& Day (2017); Clapp-Smith, Hammond, Lester \& Palanski. 2019).

Leaders' efforts to become more effective in managing others' learning style preferences can be advanced by practicing situational leadership as espoused by Hersey, Blanchard and Johnson (2012). Situational leadership is especially appropriate to use with followers who prefer to "take action" or "implement things" as their preferred learning style. Leaders are challenged to help their people recognize their readiness level (which is a key element of situational leadership) for taking action or implementing projects. According to the tenets of situational leadership, individual readiness levels relate to an individual's ability and confidence for completing a task. Individuals with low ability and confidence for the task at hand need explicit and detailed direction from their managerial leader/supervisor while those with high levels of ability and confidence need for their leader/supervisor to delegate the task to them. In all situations, however, a leader needs to establish and communicate a clear, credible and appropriate level of direction to followers (Kerns, 2017b). ${ }^{5}$

Another challenge is to ensure that business metrics are in place to connect learning outcomes to desired organizational outcomes (Froehlich, Segers \& Van den Bossche, 2014; Farrell, 2000). The process of enhancing learning and identifying as well as managing learning style preferences will need to be linked to important business results such as enhanced innovation, product development and profitability. Closely associated is the need to ensure that action learning plans associated with individual leader development are connected to an organization's strategic objectives. Learning and the management of learning preferences can be a force to help define, communicate and execute strategy (Twomey, 2005; Stock, Zacharias \& Schnellbaecher, 2017; Goldman \& Casey, 2010).

It is also going to be challenging for individual leaders to break bad habits related to applying work style preferences at work. It seems that individuals tend to over or under utilize their learning styles. Since it is desirable for leaders to display a balanced approach to managing learning styles, leaders will be challenged to draw upon relevant findings in the emerging fields of neuroscience and neuroleadership for ways to help change ineffective behavioral patterns relating to executing learning style preferences (Zull, 2002; Eyal, 2014). Based on the finding from applied experiential learning regarding the stability of preferred learning modes, these efforts to change old learning style habits among leaders will likely be challenging.

Given the advances in technological innovation, leaders and their organizations will be charged to utilize technologies to assist them in the training and development of leaders and their people to become 
more knowledgeable about learning style preferences and how to manage them. These efforts may include applying gamification principles and situational judgement testing methods to help leaders better understand and manage learning and learning style preferences at work (Fields \& Kafai, 2018; Fritzsche, Stagl, Salas, \& Burke, 2006). It would seem that this challenge could be addressed most effectively from an interdisciplinary/cross-functional approach. Information technology professionals, learning science experts and leadership practitioners would likely be key contributors to these types of cross-functional efforts. In particular given their need to link cross-functionally to educate and spark learning and innovation, Chief Marketing Officers are challenged to utilize new technologies to facilitate learning. The work of Richards and Marshall (2019) that connects experiential learning to marketing technologies provides insight in addressing this challenge.

Additionally, there is a challenge to align learning and managing learning work style preferences with efforts to create and sustain organizational cultures with strong learning identities (Kerns, in press). Leaders and their organizations need to recognize and explore ways to further connect change management and innovation with leadership driven organizational learning. Learning and managing learning preferences need to be seen as integral parts of organizational change management programs for enhancing competitiveness, performance and well-being.

Finally, leaders' efforts to enhance their understanding and management of learning and learning preferences, along with helping others do the same, needs to be seen as a way to increase organizational well-being. Leaders are challenged to see their work at managing learning preferences as a well-being enhancing process. It is well documented that employees globally want to work for bosses who show interest in their development (Kerns, 2018a). Leaders who improve their understanding in this area can serve as positive performance models for their people and can help their people better understand and manage their learning preferences and learning identities at work as appropriate. Meeting this challenge will likely help in enhancing individual, group and organizational well-being.

\section{SUMMARY STATEMENT}

Organizational leaders can benefit by having practical approaches that help them identify and manage learning and learning preferences. Effectively managing learning preferences helps positively influence competitiveness, performance and well-being. There is a need for applied researchers and practitioners to work together to find innovative ways to support leaders in their efforts to better understand and manage learning in workplace settings. As this work moves forward, there will be a need to enhance the awareness of the value of managing learning and learning preferences in organizational settings. Leaders will benefit from learning how best to motivate and develop their people as adult learners. Lessons drawn from the learning sciences and experiential learning theory, in particular, will help leaders become more skillful in managing their own and others' learning preferences. Technology assisted learning strategies and situational judgement testing methods may prove useful. The emerging work in neuroscience and neuroleadership may also help leaders become more effective in managing their learning preferences, especially when it comes to practicing infrequently used learning style preferences. All of these efforts will likely help leaders become more effective in managing learning at work for higher performance, well-being and enhanced competitiveness.

\section{ENDNOTES}

1. Over three decades a debate comparing and contrasting management and leadership has taken place. In this article the terms leader, manager, organizational leader, managerial leader, management, and leadership are used synonymously.

2. Refer to Passarelli \& Kolb (2011), Kolb \& Kolb (2005), Kolb (2017), and Kolb (1984) for a more detailed review and discussion of the learning cycle, learning style preferences and research associated with experiential learning theory. 
3. The author's system of managerial leadership strives to provide practitioners, applied researchers and teachers with an integrated approach to viewing and understanding leadership. The system brings together several streams of leadership study and research that have been offered over the past 100 years. Concurrently, the development and execution of managing learning preferences frameworks which is the focus of the current article can help advance the practice, study and teaching of leadership. It is, however, beyond the scope of the current presentation to review and discuss the other system dimensions and related practices.

4. This example is drawn from the author's work as an executive coach/trusted advisor with a key executive. For confidentiality purposes, identifying information has been changed.

5. See Hersey, Blanchard \& Johnson (2012) for a more detailed review and discussion of situational leadership. Also, see Kerns (2017) for further discussion regarding providing direction as a key managerial leadership practice.

\section{REFERENCES}

Akhavan, P., Zahedi, M.R., Dastyari, A., \& Abasaltian, A. (2014). The effect of organizational culture, leadership style on knowledge management in selected research organizations. International Journal of Scientific Management \& Development, 2(9), 432-440.

Andreadis, N. (2009). Learning and organizational effectiveness: A systems perspective. Performance Improvement, 48(1), 5-11

Aragón-Correa, J.A., Garcia-Morales, V.J., \& Cordón-Pozo, E. (2007). Leadership and organizational learning's role on innovation and performance: Lessons from Spain. Industrial Marketing Management, 36(3), 349-359.

Bligh, M.C., Kohles, J.C., \& Yan, Q. (2018). Leading and learning to change: The role of leadership style and mindset in error learning and organizational change. Journal of Change Management, 18(2), $116-141$.

Caza, B.B., \& Wrzesniewski, A. (2013). How work shapes well-being. In S.A. David, I. Boniwell \& A.C. Ayers (Eds.), The oxford handbook of happiness (pp. 693-710). New York, NY: Oxford University Press.

Clapp-Smith, R., Hammond, M.M., Lester, G.V., \& Palanski, M. (2019). Promoting identity development in leadership education: A multidomain approach to developing the whole leader. Journal of Management Education, 43(1), 10-34.

Clouse, R.W., Wilson, S., \& Rizzo, R. (2019). A cross-disciplinary entrepreneurship commercialization process model: Learning in action. Journal of Marketing Development \& Competitiveness, 13(2), 116-142.

Coffield, R., Moseley, D., Hall, E., \& Ecclestone, K. (2004). Learning styles and pedagogy in post-16 learning. A systematic and critical review. London, UK: Learning and Skills Research Centre.

DiBella, A.J. (2001). Learning practices: Assessment and action for organizational improvement. Upper Saddle River: NJ: Prentice Hall.

Dweck, C.S. (2000). Self theories: Their role in motivation, personality, and development. New York, NY: Taylor \& Francis Group.

Dweck, C.S. (2006). Mindset: The new psychology of success. New York, NY: Random House.

Eyal, N. (2014). Hooked: How to build habit-forming products. New York, NY: Portfolio/Penguin.

Fabritius, F., \& Hagermann, H.W. (2017). The leading brain: Powerful science-based strategies for achieving peak performance. New York, NY: Penguin Random House.

Fazey, J.A., \& Marton, F. (2002). Understanding the space of experiential variation. Active Learning in Higher Education, 3, 234-250.

Fields, D.A., \& Kafai, Y.B. (2018). Games in the learning sciences: Reviewing evidence from playing and making games for learning. In F. Fischer, E.E. Hmelo-Silver, S. R. Goldman, \& P. Reiman (Eds.). International handbook of learning sciences (pp. 276-284). New York, NY: Routledge. 
Finkelstein, S. (2018). The best leaders are great teachers. Harvard Business Review, January - February, p. 142-145.

Fritzsche, B.A., Stagl, K.C., Salas, E., \& Burke, C.S. (2006). Enhancing the design, delivery, and evaluation of scenario-based training: Can situational judgement tests contribute? In J.A. Weekly \& R.E. Ployhart. Situational judgement tests: Theory, measurement and application (pp. 301318). New York, NY: Psychology Press.

Froehlich, D., Segers, M., \& Van den Bossche, P. (2014). Informal workplace learning in Austrian banks: The influence of learning approach, leadership style, and organizational learning culture on managers' learning outcomes. Human Resource Development Quarterly, 25(1), 29-57.

Goldman, E.F. \& Casey, A. (2010). Building a culture that encourages strategic thinking. Journal of Leadership \& Organizational Studies, 17(2), 119-128.

Herrenkohl, L.R., \& Polman, J.L. (2018). Learning within and beyond the disciplines. In F. Fischer, E.E. Hmelo-Silver, S.R. Goldman \& P. Reiman (Eds.). International handbook of the learning sciences (pp. 106-115). New York, NY: Routledge.

Hersey, P., Blanchard, K.H., \& Johnson, D.E. (2012). Management of organizational behavior (10th Ed.). Upper Saddle River, NJ: Prentice Hall.

Heslin, P.A. (2010). Mindsets and employee engagement: Theoretical linkages and practical interventions. In S. Albrecht (Ed.), The handbook of employee engagement: Perspectives, issues, research and practice (pp. 218-226). Cheltenham, UK: Edwin Elgar.

Hoadley, C. (2018). A short history of learning sciences. In F. Fischer, E.E. Hmelo-Silver, S.R. Goldman \& P. Reiman (Eds.). International handbook of the learning sciences (pp. 11-23). New York, NY: Routledge.

Kaiser, R.B., \& Overfield, D.V. (2010). Assessing flexible leadership as a mastery of opposites. Consulting Psychology Journal: Practice and Research, 62, 105-118.

Kerns, C.D. (2001). The power of performance profiling: Eight good reasons to concentrate on results. Graziadio Business Review, 4(1).

Kerns, C.D. (2010). [Strengths in Action Behavioral Checklist (S-ABC)]. Unpublished instrument.

Kerns, C.D. (2014). Fostering and managing engagement: A framework for managerial leaders. Journal of Leadership, Accountability and Ethics, 11(1), 34-49.

Kerns, C.D. (2015a). Individual differences: A core leadership dimension. International Leadership Journal, 7(1), 54-77.

Kerns, C.D. (2015b). Situational context: A core leadership dimension. Journal of Leadership, Accountability and Ethics, 12(1), 11-24.

Kerns, C.D. (2016). [The Values Profiling and Prioritizing Checklist]. Unpublished instrument.

Kerns, C.D. (2017a). Managing leader core values at work: A practice-oriented approach. Journal of Leadership, Accountability and Ethics, 14(1), 11-21.

Kerns, C.D. (2017b). Providing direction: A key managerial leadership practice. Journal of Applied Business and Economics, 19(9), 25-41.

Kerns, C.D. (2018a). Impacting well-being at work: A key managerial leader action role. Journal of Management Policy and Practice, 19(1), 73-91.

Kerns, C.D. (2018b). Leader life-span experience management. A practice-oriented approach. Journal of Applied Business and Economics, 20(8), 105-119.

Kerns, C.D. (2019a). Leading thought leadership: A practice-oriented framework. International Leadership Journal, 11(1), 3-41.

Kerns, C.D. (2019b). Leadership presence at work: A practice-oriented framework. Journal of Marketing Development and Competitiveness, 13(3), 91-109.

Kerns, C.D. (2019c). Managing teamwork: A key leadership practice. Journal of Leadership, Accountability and Ethics, 16(1), 40-53.

Kerns, C.D. (in press). Managing organizational culture: A practice-oriented framework. International Leadership Journal. 
Kerns, C.D., \& Ko, K. (2014). Managerial leadership competencies: A practice-oriented action role framework. International Leadership Journal, 6(1), 82-99.

Kharabsheh, R.A., Jarrar, K., \& Simeonova, B. (2015). The impact of competitive strategies on responsive market orientation, proactive market orientation, learning orientation and organizational performance. Journal of Strategic Marketing, 23(5), 423-435.

Knowles, M.S., Holton III, E.F., \& Swanson, R.A. (2015). The adult learner (8th ed.). New York, NY: Routledge.

Kolb, A.Y., \& Kolb, D.A. (2005). Learning styles and spaces: Enhancing experiential learning in higher education. Academy of Management Learning and Education, 4(2), 193-212.

Kolb, D.A. (1984). Experiential learning: Experience as the source of learning and development. Upper Saddle River, NJ: Prentice Hall.

Kolb, D.A. (2017). Kolb learning style inventory: Workbook version 3.2. Retrieved from www.learningfromexperience.com.

Larrea, J.L., Aranguren, M.J., \& Valdaliso, J.M. (2017). Exploring the role of leadership in territorial strategies for competitiveness. Competitiveness Review, 27(4), 390-409.

Leavy, B. (1999). Organization and competitiveness - towards a new perspective. Journal of General Management, 24(3), 33-52.

Locke, E.A. (2007). The case for inductive theory building. Journal of Management, 33, 867-890.

Locke, E.A., Cooper, C.L. (2000). Conclusion: The challenge of linking theory to practice. In C.L. Cooper and E.A. Locke (Eds.), Industrial and organizational psychology: Linking theory with practice (pp. 335-341). Malden, MA: Blackwell.

Ludvigsen, S., \& Nerland, M. (2018). Learning at work: Social practices and units of analysis. In F. Fischer, E.E. Hmelo-Silver, S.R. Goldman \& P. Reiman (Eds.). International handbook of the learning sciences (pp. 147-156). New York, NY: Routledge.

Mainemelis, C., Boyatzis, R., \& Kolb, D.A. (2002). Learning styles and adaptive flexibility: Testing experiential learning theory. Management Learning, 33(1), 5-33.

Michie, J., \& Zumitzavan, V. (2012). The impact of learning and leadership management styles on organizational outcomes: A study of tyre firms in Thailand. Asia Pacific Business Review, 18(4), 607-630.

Migliore, R.H., Howard, N.C., \& Gray, D.M. (2018). Contemporary marketing evolves. Journal of Marketing Development and Competitiveness, 12(2), 98-104.

Miscenko, D., Guenter, H., \& Day, D.V. (2017). Am I a leader? Examining leader identity development over time. Leadership Quarterly, 28, 605-620.

Molden, D.C., \& Dweck, C.S. (2006). Finding "meaning" in psychology: A lay theories approach to selfregulation, social, perception, and social development. American Psychologist, 61(3), 192-203.

Mumford, M.D., \& Higgs, C.A. (2020). Leader thinking skills: Capacities for contemporary leadership. New York, NY: Routledge.

Oc, B. (2018). Contextual leadership: A systematic review of how contextual factors shape leadership and its outcomes. Leadership Quarterly, 29, 218-235.

Pashler, H., McDaniel, M., Rohrer, D., \& Bjork, R. (2009). Learning styles concepts and evidence. Psychological Science in the Public Interest, 9(3), 105-119.

Passarelli, A.M., \& Kolb, D.A. (2011). The learning way: Learning from experience as the path to lifelong learning and development. In M. London (Ed.). The oxford handbook of lifelong learning (pp. 7090). New York, NY: Oxford University Press.

Putz, D., Schilling, J., Kluge, A., \& Stangenberg, C. (2012). Measuring organizational learning from errors: Development and validation of an integrated model and questionnaire. Management Learning, 33, 511-536.

Renninger, K.A., Ren, Y., \& Kern, H.M. (2018). Motivation, engagement, and interest: "In the end, it came down to you and how you think of the problem". In F. Fischer, E.E. Hmelo-Silver, S.R. Goldman \& P. Reiman (Eds.). International handbook of the learning sciences (pp. 116-126). New York, NY: Routledge.

26 Journal of Leadership, Accountability and Ethics Vol. 16(5) 2019 
Richards, M.B., \& Marshall, S.W. (2019). Experiential learning theory in digital marketing communication: Application and outcomes of the applied marketing \& media education norm (AMEN). Journal of Marketing Development and Competitiveness, 13(1), 86-98.

Roberts, L.M. (2013). Reflected best self engagement at work: Positive identity alignment, and the pursuit of vitality and value creation. In. S.A. David, I. Boniwell \& A.C. Ayers (Eds.). The oxford handbook of happiness (pp. 767-782). New York, NY: Oxford University Press.

Rybowiak, V., Garst, H., Frese, M., \& Batinic, B. (1999). Error orientation questionnaire (EOQ): Reliability, validity, and different language equivalence. Journal of Organizational Behavior, 20, 527-547.

Schyns, B., Kiefer, T., Kerschreiter, T., \& Tymon, A. (2011). Teaching implicit leadership theories to develop leaders and leadership: How and why it can make a difference. Academy of Management Learning \& Education, 10(3). 397-408.

Shimoni, B. (2017). What is resistance to change? A habitus-oriented approach. Academy of Management Perspectives, 31, 257-270.

Sternberg, R.J., \& Zhang, L. (2005). Styles of thinking as a basis of differentiated instruction. Theory into Practice, 44(3), 245-253.

Sternberg, R.J. (1997). Thinking styles. New York, NY: Cambridge University Press.

Stock, R.M., Zacharias, N.A., \& Schnellbaecher, A. (2017). How do strategy and leadership styles jointly affect co-development and its innovation outcomes? Journal of Product Innovation Management, 34(2), 201-222.

Swart, T., Chisholm, K., \& Brown, P. (2015). Neuroscience for leadership: Harnessing the brain gain advantage (The neuroscience of business). London, UK: Palgrave Macmillan.

Swift, P.E. \& Hwang, A. (2008). Learning, dynamic capabilities and operating routines: A consumer package goods company. Learning Organization, 15(1), 75-95.

Tannenbaum, S.I., Beard, R.L., McNall, \& Salas, E. (2012). Informal learning and development in organizations. In S.W.J. Kozlowski \& E. Salas (Eds.). Learning, training and development in organizations (pp. 303-331). New York, NY: Routledge.

Tomkins, L., \& Pritchard, K. (2020). Health at work: Critical perspectives. New York, NY: Routledge.

Tran, T. (2008). A conceptual model of learning culture and innovation schema. Competitiveness Review, 18(3), 287-299.

Turesky, E.F., \& Gallagher, D. (2011). Know thyself: Coaching for leadership using Kolb's experiential learning theory. The Coaching Psychologist, 7(1), 5-14.

Twomey, D.F. (2005). Global competitiveness: Financial manager's leadership role in knowledge creation. Journal of Global Competitiveness, 13(1 \& 2), 37-45.

Venus, M., Stam, D., \& van Knippenberg, D. (2019). Visions of change as visions of continuity. Academy of Management Journal, 62(3), 667-690.

Wyrick, D.A. (2003). Understanding learning styles to be a more effective team leader and engineering manager. Engineering Management Journal, 15(1). 27-33.

Zaccaro, S.J., Green, J.P., Dumbrow, S., \& Kolze, M. (2018). Leader individual differences, situational parameters, and leadership outcomes: A comprehensive review and integration. Leadership Quarterly, 29, 2-43.

Zahay, D., Altounian, D., Pollitte, W., \& James, J. (2019). Effective resource deployment in digital marketing education. Marketing Education Review, 29(3), 182-192.

Zull, J.E. (2002). The art of changing the brain: Enriching teaching by exploring the biology of learning. Sterling, VA: Stylus. 